\title{
Obituaries
}

Obituaries should be submitted by email to Jadene Doak at jadene.doak@springernature.com

All submitted obituaries should be 400 words maximum in length (apart from obituaries for past presidents of the BDA where the length should be 800 words).

Content of the obituary is down to the individual author, and the approval of the family should be given for the obituary prior to submission to the BDJ.

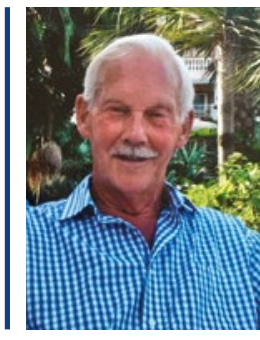

\section{Roy Duckworth CBE}

$1929-2020$

Roy died peacefully on 16 September 2020 , aged 91 . He is survived and missed by his beloved wife Marjorie, sons Michael and Stephen, daughter Anne, nine grandsons, former colleagues at the Royal London Hospital, and friends worldwide.

Roy Duckworth qualified in both dentistry and medicine at the University of Liverpool, subsequently gaining several higher qualifications. After service in the RAF Dental Branch, he moved to London in 1959 as a Nuffield Fellow to work at the Royal Postgraduate Medical School and Guy's Hospital Dental School. He joined the staff of the London (now Royal London), Whitechapel in 1961 and remained there for the rest of his very distinguished career.

Roy made rapid progress through the academic ranks, becoming Professor and Head of the Department of Oral Medicine and Periodontology in 1968. In 1969, he took over the mantle of the Dean of Dental Studies from Geoffrey Slack and carried out those duties with great distinction for six years. From 1986-94, Professor Duckworth was Dean of the Medical College at a time of great change when a clear mind and steady hand at the helm were essential.

Outside The London, Roy made many significant contributions to the profession. He was elected Dean of the Faculty of Dental Surgery of the Royal College of Surgeons in 1983, and also held office at various times as President of the British Society of Periodontology, the British Society of Oral Medicine, and the British

Dental Association in 1990. He served on numerous important committees and advisory bodies, both nationally and internationally, and was Editor of the International Dental Journal for many years. Professor Duckworth's outstanding contributions were very deservedly recognised by the award of the CBE in 1987. It was highly appropriate for Roy to be one of the first recipients of the Geoffrey Layton Slack Medal, since he was a patient of Geoffrey prior to taking up dentistry as a career.

For those who have had the privilege of working with Roy Duckworth over the years, he remained above all a good friend and a respected colleague.

Stephen Duckworth

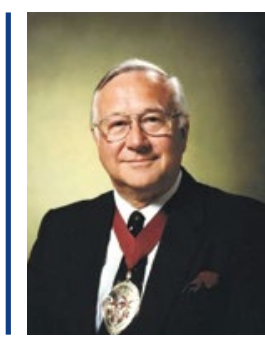

\section{Russell Hopkins OBE}

1932-2020

Born in Sunderland on 30 April 1932, Russell Hopkins went to dental school in Newcastle, followed by dental practice in Hartlepool, Cambridge, Salisbury, and Southern Rhodesia developing an interest in general anaesthesia. Returning to an SHO post at Nottingham General Hospital including maxillofacial injuries, he worked for Tom Battersby, treating a population of 2 million, including all facial traumas. Russell worked hard, had natural surgical talent and gave the anaesthetics for two GA lists weekly in $\mathrm{A} \& \mathrm{E}$.

As registrar in Chertsey he came under the influence of Norman Rowe. Medical school followed at the Royal Free, with medicine in Croydon and surgery at
Bolinbrook Hospital where he befriended his resident surgical officer, Bill Heald.

After a senior registrar post in Newcastle, he was appointed consultant in OMFS in Cardiff, establishing himself with his then senior registrar, Khursheed Moos. Hospital consultants were held in low esteem by the dean and some academics and he was not allowed to teach students. They nevertheless queued to join his clinics and operating lists. He took over facial trauma management in Cardiff becoming chair of dental staff, and then medical staff, establishing joint clinics in orthodontics with Derek Seel, and in maxillofacial prosthetics with John Bates, and then significantly with Derek Stafford. He was proud of giving trainees quality surgical training and of their subsequent distinguished careers. In 1970 he married Jill and they had three children, Richard, Claire, and Robert.

Russell sat on several national BMA committees and between 1985 and 1991 became general manager of the University Hospital of Wales, one of the first clinicians to be a senior manager. He rectified some deplorable conditions of the estate and took on vested interests that short changed the NHS and was awarded an OBE in 1989.

President of BAOMS in 1993, he went on to chair health trusts. He could be tough, provocative, and outrageous, but could also be a delight to work with. $\mathrm{He}$ wrote in his autobiography, 'Some clinical managers forgot they were clinicians and that ethical and quality care of patients was their number one priority. Because of this an increasing number of NHS disasters filled the headlines'. He had no idea that he would become one of its victims. Eventually his medical problems caught up with him and he died peacefully in his sleep on 2 February 2020.

Adrian Sugar 